\title{
Publicidad y prensa: algunas posibles líneas de investigación
}

\section{Advertising and the Press: Some possible lines of research}

\section{Claudio Durán}

Senior Scholar, Department of Philosophy, York University

cduran@yorku.ca

\begin{abstract}
Resumen
Este artículo intenta presentar seis líneas de investigación de la publicidad así como aparece en la prensa. Estas líneas de investigación son menos frecuentes y tratan de contribuir con ideas acerca de la naturaleza de la publicidad. Mientras que usualmente sucede que la publicidad se aprecia como estrechamente relacionada a la sociedad capitalista, de manera tal que su evaluación parece depender del modo como se evalúe al capitalismo, claramente toda evaluación ecuánime debe tomar en cuenta la naturaleza de la publicidad.
\end{abstract}

Palabras clave: Capitalismo, líneas de investigación, naturaleza de la publicidad, publicidad.

\begin{abstract}
This article intends to present six lines of research of advertising as it appears in the press. These lines of research are less frequent and they attempt to contribute ideas about the nature of advertising. While it usually happens that advertising is understood as closely related to the capitalist society, such that its evaluation tends to depend on whether capitalism is perceived as positive or negative, clearly all fair evaluations must take into account the nature of advertising.
\end{abstract}

Key words: Advertising, capitalism, lines of research, nature of advertising.

Con el producto comercial de los anuncios, los periódicos han podido pagar mejor a sus escritores, destinar hombres de gran talento a buscar informaciones, contratar servicios extranjeros que abarcan toda la extensión de la tierra, reproducir dibujos y fotografías, invadir el campo de la revista literaria y científica con sus 
suplementos y editar esos volúmenes en que hombres y mujeres de la más varia cultura y más opuestos gustos hallan satisfecha su curiosidad.

En el diario moderno predomina el anuncio. Síguele en importancia la información noticiosa interna y externa. $Y$ en esta información tienen sitio prominente las noticias que se refieren a los gustos e intereses del mayor número, como los deportes, el cinematógrafo, el comercio. Y los anuncios mismos son noticias, pues avisan al lector que tal cosa se vende o tal otra se compra, ponen en contacto a miles de hombres que tienen conveniencia en encontrarse y entrar en relaciones comerciales. El diario moderno resulta una vasta amplificación de la primitiva gaceta destinada sólo a dar cierta clase de noticias.

Se diría que esto restringe cada día el espacio y el interés dedicados a la propaganda de opiniones y doctrinas. La restricción es más aparente que real. El diario sigue distribuyendo influencias espirituales, las desliza en sus telegramas del país y del extranjero, las infunde en cada línea de noticias al parecer inofensivas, hace más con esa masa de informaciones que con los antiguos extensos artículos y ásperas polémicas para inclinar al lector, poco a poco, insensiblemente, hacia este o aquel convencimiento".

[Ennegrecido es del autor de este artículo]. Carlos Silva Vildósola, Medio Siglo de Periodismo (1938)

Esta época se caracteriza por un extraordinario despliegue y acumulación de imágenes visuales. Muchas de ellas se refieren a imágenes publicitarias. Seguramente una gran mayoría. El autor James Twitchell (1996) en su libro, AdCult USA ${ }^{1}$, señala que las personas que habitan en Estados Unidos ven, explícita o implícitamente, alrededor de tres mil imágenes publicitarias al día. John Berger (1977) se refiere a este mismo fenómeno que se confronta, día a día, en las sociedades capitalistas. Nunca antes de esta época, habían los seres humanos enfrentado esta realidad. La producción y existencia de esta enorme cantidad de imágenes visuales podría relacionarse con la caracterización que Marx (1954) hace al comienzo de El Capital: la sociedad en que predomina el modo de producción capitalista consiste en una inmensa acumulación de mercancías. El efecto -o los efectos- de la publicidad es un tema altamente controversial, pero la verdad es que, muy probablemente, la sociedad capitalista no podría funcionar efectivamente sin publicidad. ¿Por qué sería esto así? ¿Acaso los seres humanos son susceptibles a la persuasión publicitaria de un modo que ella mine los cimientos de lo que en la tradición occidental se ha llamado la racionalidad? ¿Sucede, tal vez, que la educación en

1 Traducciones de textos en inglés hechas por el autor. 
su conjunto no ha sido suficientemente potente para impedir la penetración de ideas bajo el nivel de la conciencia? ¿O habría que preguntarse si ninguna educación basada solamente en la lógica puede generar recursos para impedirlo? Finalmente, ¿no se estará exagerando el papel persuasivo de la publicidad, y lo que realmente ocurre es que ella no es más que la información que se necesita para saber lo que en el mercado se ofrece como bienes y servicios?

Algunos/as publicistas argumentan que su función es dar a conocer esos bienes y servicios de una manera creativa, artística, entretenida e incluso objetiva. Agregan que un/a publicista tiene el deber de operar de una manera ética, no pudiendo utilizar su experiencia para dar a conocer productos o servicios que, a sabiendas, son de mala calidad. En este sentido, comparan ellos/as su labor con la de educadores/as. En efecto, es esperable, por supuesto, que un/a profesor/a tiene que enseñar de manera técnicamente impecable, sin engañar al alumnado, y haciendo posible que lo que se enseña pueda ser examinado y valorado por alumnos/as, así como por otros/as especialistas. En el caso de los publicistas, sigue el argumento, su trabajo hace posible el funcionamiento efectivo del mercado.

Sin embargo, al menos desde la publicación del libro de Vance Packard (1957), The Hidden Persuaders, siempre ha habido una sospecha de que la publicidad constituye un caso flagrante de persuasión indebida y que opera bajo los niveles de la conciencia. Packard argumenta que muchos publicistas han hecho uso de los conocimientos derivados de las ciencias sociales, de la psicología, de la psiquiatría, del psicoanálisis, por ejemplo, para desarrollar técnicas altamente sofisticadas en orden a persuadir ocultamente. Si así fuese, las sociedades modernas estarían siendo manipuladas de maneras éticamente cuestionables, dadas las expectativas de la civilización occidental. El libro de Packard dejó de publicarse hace más de una década, pero hoy en día ha aparecido una suerte de sucedáneo suyo en el libro de Martin Lindstrom (2011), Brandwashed, en que se expone la tesis de que una cantidad significativa de persuasión publicitaria actual está fundada en la investigación acerca del cerebro humano.

Como quiera que sea la utilización de los avances de las ciencias sobre lo humano por parte de la publicidad, la inquietud central deviene, entonces, en si los seres humanos, en la sociedad capitalista, funcionan de un modo racional y ético en lo que se refiere a los hábitos de consumo. El mismo John Berger dice que la publicidad, fenómeno que este autor relaciona fundamentalmente al capitalismo como modo de producción, constituye, en esencia, una manera de manufactura del glamour, y este concepto lo define en términos de un estado de sentirse envidiado. Por lo tanto, la sociedad capitalista devendría en una serie casi interminable de procesos glamorosos que envuelven envidia. Si las cosas ocurrieran de este modo, por decir lo menos, la imagen de lo humano entraría en profunda contradicción con la mayoría de los ideales que nuestra sociedad occidental ha mantenido por siglos.

En todo caso, y dejando esa línea de argumentación para más adelante, hay ciertas cosas que son claramente efectivas. En el libro de los autores Fred Siebert, Theodor Peterson y Wilbur Schramm (1984), Four Theories of the Press, se pone de manifiesto que la prensa libertaria, característica de las sociedades liberales-democráticas capitalistas, ha adoptado la función 
publicitaria como absolutamente necesaria para mantener el carácter objetivo de la prensa. Sostienen ellos que la prensa libertaria tiene cinco funciones principales: las tres primeras son información, entretención y publicidad, que hacen posible el financiamiento de la prensa libre. De ese modo, la prensa no requiere de la ayuda gubernamental para su funcionamiento, haciendo posible que pueda ser independiente y objetiva. Sobre todo, porque las funciones cuarta y quinta de la prensa libertaria se refieren a la presentación de la verdad, aunque esta perjudique al gobierno, y además, se trata de que la prensa pueda servir para criticar al gobierno cuando este trate de imponerse arbitrariamente a la ciudadanía. Ahora bien, el libro aduce que la función publicitaria nunca fue claramente delimitada por la teoría libertaria y que siempre se mantuvo una cuota de incertidumbre acerca de ella.

Sin embargo, estos autores también sostienen que el desarrollo unilateral de esa teoría de la prensa culminó en una inmensa concentración de poder en manos de empresarios capitalistas, quienes lo emplean para servir a sus propios intereses y no a los de la sociedad en su conjunto. También, dicen, agencias publicitarias habían presionado a la prensa para responder a las necesidades de las empresas, incluyendo supresión de noticias negativas para ellas, es decir, una imposición indebida sobre la línea editorial de los diarios. La crítica a la teoría libertaria fue creciendo cada vez más, y esto llevó al desarrollo de otra teoría que los autores llaman de responsabilidad social. Esta última teoría mantiene la base capitalista de la sociedad en el aspecto económico, pero pone restricciones al poder desmedido de la teoría anterior. Incluso, acepta que algún tipo de agencia social, incluyendo al gobierno si fuera necesario, podría intervenir en el caso de que la prensa o la publicidad derivaran en políticas negativas para la sociedad. La teoría de responsabilidad social mantiene las mismas funciones de la teoría libertaria, pero dentro de un espectro mucho mayor de responsabilidad ética. En cuanto a la publicidad, la nueva teoría es cauta, más aun, se llegó a considerarla como una fuerza siniestra, la cual había que vigilar.

Hoy en día, se podría decir que la teoría libertaria está representada por las políticas neoliberales, y que la teoría de responsabilidad social se relaciona más bien con las políticas de centro, o centro-izquierda, y en especial con las posiciones social-demócratas.

Volviendo ahora a John Berger (1977), este autor argumenta también que la publicidad es un mecanismo fundamental para impedir un mayor desarrollo de democracia en las sociedades capitalistas. Sostiene Berger que las sociedades capitalistas, sobre todo en occidente, detuvieron su avance a mayores grados de democracia, para concentrarse más bien en el consumo. Este último devino en el objetivo de la gente. Sin embargo, el consumo no puede reemplazar a la democracia, más bien, todo lo contrario: impide su desarrollo. El consumo, por otra parte, es el equivalente tangible de la publicidad, y esta es, Berger dice, el sueño del capitalismo. Sin este sueño el capitalismo no puede sobrevivir.

John Berger lleva las críticas que la teoría de responsabilidad social hace a la publicidad a un nivel más profundo, al cuestionar las bases capitalistas mismas en el manejo de la economía. Se puede, en este punto, relacionar sus ideas con las posiciones que mantienen que la publicidad se vale de los avances de las ciencias acerca de lo humano para inducir persuasión oculta. 
Ahora bien, si es efectivo que la publicidad es esencial al desarrollo del capitalismo, se llegaría a concluir que las sociedades del presente capitalista del mundo se sostienen en medida muy importante, no solamente en la manipulación oculta, sino además, lo que es más preocupante, en ensoñaciones y fantasías dañinas para la especie humana en su conjunto.

En este punto, es necesario introducir en esta argumentación la visión ya establecida, no solo en las ciencias sociales, sino en la gente en general, de la sociedad de consumo. En países capitalistas desarrollados, y aun en aquellos de menor desarrollo económico, parece funcionar la idea de que el consumo es el objetivo de la vida. Por supuesto, el consumo es necesario, pero el concepto de sociedad de consumo lleva a otra dimensión de la experiencia humana: el consumo es, sin duda, necesario para la vida humana, pero si la vida humana se define en términos de consumir, entonces los valores de esta especie se transmutan precisamente en consumir y consumir más y más, sin límites.

Tal vez, uno de los autores que con más profundidad ha conceptualizado este fenómeno es el teórico político canadiense C.B. Macpherson $(1962,1973)$, quien ha introducido ideas claves para entender el desarrollo de las sociedades capitalistas. Macpherson introdujo, en primer lugar, la idea del capitalismo como ligado al "individualismo posesivo", es decir, la idea de que la esencia humana se reduce a la posesión de cosas materiales. Pero, en el estadio de estas sociedades como se presenta en la actualidad, la idea que subyace a lo que vive la especie humana, es la del "apropiador infinito", y más centralmente, del "consumidor infinito". En este sentido, basta revisar de una manera somera la prensa, o mirar la televisión o escuchar la radio, para enfrentar la presión ilimitada de la publicidad. Como dice John Berger (1977), la publicidad consiste en la ilusión de que el consumo es una manifestación central de la democracia.

La relación profunda entre capitalismo y publicidad no solamente aparece explícita en críticos/as del capitalismo, sino también, en autores que aprecian positivamente esa relación. Así, John Gloag (1959) sostiene que la publicidad es el signo más visible de la sociedad de libre empresa, y que esa es la razón de que exista tanta crítica por parte de autores que la miran con recelo. Por su parte, James Twitchell (1996) dice:

La publicidad constituye el programa educacional del capitalismo, el arte apoyado por el capitalismo, el lenguaje del capitalismo, la pornografía del capitalismo. Sobre todo, aparte de todas las frases rimbombantes, la publicidad es la cultura desarrollada para resolver el problema central del capitalismo: la distribución de los bienes excedentes. La revolución industrial se estudia por lo general desde el punto de vista de los productores, de cómo las máquinas fabrican cosas. Pero, la revolución real fue cómo las cosas se distribuyeron, cómo la publicidad hizo que las cosas fueran dignas de comprarse ( $\mathrm{p}$. 41).

Para concluir esta parte del artículo, se puede decir, en síntesis, que la evaluación de la publicidad parece depender fundamentalmente de la evaluación que se haga del capitalismo. 
Sin embargo, se debe tener claridad sobre el hecho de que la publicidad tiene una naturaleza tal que ella no se reduce al capitalismo. Por lo tanto, es importante investigar acerca de su naturaleza y, tal vez, determinar la medida en que ella depende del capitalismo solamente sobre la base de una investigación cuidadosa.

A continuación, se expone una serie de seis posibles líneas de investigación sobre la publicidad, sobretodo en la prensa. Por supuesto, hay una gran variedad de maneras de investigar la publicidad, en este artículo se presentan líneas de investigación que son poco frecuentes.

En primer lugar, se puede señalar la investigación desarrollada por Lagos, Checa, Cabalin y Peña y Lillo ${ }^{2}$ que intenta explorar la posibilidad de que un estudio de largo aliento sobre la inversión publicitaria en la prensa, pueda servir de base al análisis de la influencia negativa de la publicidad sobre la línea editorial de los diarios. En especial, determinar si las empresas y las agencias de publicidad pueden afectar negativamente a la libertad de prensa. Esta idea se encontró anteriormente en este artículo en referencia a la crítica que hace la teoría de responsabilidad social a la publicidad y al capitalismo que funcionan sin regulaciones. Este tipo de estudio tiene importancia para entender el poder de la publicidad en las sociedades capitalistas.

En segundo término, y dada las características de la publicidad como queda de manifiesto en la parte teórica de este trabajo, se puede indagar la relación cuantitativa en la prensa entre las noticias, los editoriales, los comentarios, las cartas al director, etc., y por otra parte, la publicidad. La pregunta sería ¿qué proporción hay entre ambas clases de contenidos? Esta investigación supone varios aspectos. Simplemente, es una manera de tener en claro la penetración de la publicidad entre noticias, comentarios, editoriales, etc. Así, se trata de entender el modo como la publicidad se inmiscuye en la función principal de la prensa, vale decir, la información sobre la realidad y el análisis que se necesita para entender la sociedad. En este sentido, se debe determinar la proporción entre el espacio dedicado a uno y otro de estos contenidos. A manera de ejemplo, se cita un estudio de este tipo realizado por este autor entre el 22 y 28 de noviembre de 2012 en el diario El Mercurio de Santiago. Se midió el espacio ocupado por cada contenido en los cuerpos A, B y C de este diario. De las 514 páginas de dichos cuerpos durante esa semana, la publicidad ocupó 215,79 páginas, por lo tanto, un 41,98\% del total de los tres cuerpos.

Otro aspecto envuelto en esta segunda clase de investigación, consiste en el análisis de los tipos de avisos publicitarios que aparecen en un período de tiempo. Por ejemplo, ¿qué productos o servicios se ofrecen? Y esto se debe realizar en cada cuerpo de un diario determinado a analizar. Además, es importante estudiar las yuxtaposiciones entre ambos contenidos, es decir, qué productos o servicios se yuxtaponen a qué especie de noticias.

2 Ver los artículos "Cobertura de prensa del caso 'Colusión de las Farmacias': Análisis de contenido" y "El periodismo y la libertad de prensa frente a una noticia ícono: primeros resultados cualitativos", publicados en este mismo número. 
Finalmente, y en un sentido tal vez más profundo, podría indagarse la relación entre los aspectos que podríamos llamar "racionales" y los "irracionales o no-racionales" que aparecen en la prensa. En esta perspectiva, los primeros de estos aspectos, prima facie, estarían representados por la información y análisis, y los segundos por la publicidad. Esta idea la desarrolló el académico Gerald Vise ${ }^{3}$ de York University en las décadas de 1970 y 1980. El punto esencial es aquí que la información y el análisis responden más bien a la tradición epistemológica de occidente, esto es, a la tradición lógica y científica occidental. Pero la publicidad se refiere a manifestaciones no-racionales, aun irracionales si pensamos en la manipulación bajo el nivel de la conciencia, como vimos en la primera parte de este artículo. Si se aplica esta manera de ver a los datos del estudio de El Mercurio mencionados antes, se podría decir entonces que la parte racional de este diario en esa semana fue de 58,02\% mientras que la parte no-racional e irracional constituyó 41,98\%. Mirado de esta manera, se concluiría que la lectura del diario nos confronta con una combinación sorprendente entre ambas clases de contenidos. Si es así, la tentación sería decir que la cobertura diaria incluye racionalidad y no-racionalidad en proporciones casi equivalentes.

Este aspecto tiene gran importancia, y ello será visto en más detalle al presentar la última línea de investigación. Por supuesto, hay una serie de cuestiones sutiles que investigar en estos aspectos. Por una parte, más bien se podría tomar el punto de vista de lo que dicen publicistas sobre su trabajo: la publicidad es un modo de informar sobre bienes y servicios disponibles en la sociedad, y esa información se hace de una manera creativa, artística, entretenida, etc. Como se vio antes, los diarios necesitan de la publicidad para el desarrollo de su trabajo específico, que es informar sobre la realidad social, política y económica de un país y del resto del mundo. Sin embargo, aun en ese sentido, cabe preguntar por las yuxtaposiciones entre contenidos de una y otra clase. Así, se puede investigar, por ejemplo, si noticias angustiosas se yuxtaponen a imágenes publicitarias en que aparezcan situaciones que envuelven alegría, o cosas muy positivas. Claro está, esta investigación debe hacerse abiertamente con el objeto de determinar la manera en que se encuentran dichas yuxtaposiciones.

Una tercera línea de investigación es también interesante. Consiste en la determinación de la relación entre publicidad específicamente capitalista y aquella que sirve más bien a actividades de responsabilidad social. Esta distinción hace eco de la diferencia entre la teoría libertaria y la teoría de responsabilidad social. Una imagen publicitaria que se refiere a la Teletón, por ejemplo, sería más justo clasificarla como de responsabilidad social, mientras que otra que publicita una marca de automóviles se clasificaría como capitalista. En general, aquella publicidad que presenta casos de ayuda a quienes lo necesitan, estaría en la clase de publicidad

3 El profesor Gerald Vise y este autor enseñaron conjuntamente en un curso de comunicación humana y de masas en las décadas de 70 y 80, en donde Vise dio a conocer esta idea por primera vez. Posteriormente, y durante muchos años, Vise hizo presentaciones sobre esta idea en los propios cursos sobre comunicación de masas de este autor. Numerosos estudiantes hicieron investigaciones a partir de la idea de Gerald Vise. 
de responsabilidad social, mientras que la que se refiere a ventas de todo tipo destinadas a la ganancia empresarial, sería capitalista. Esta distinción, a veces, presenta casos limítrofes. Pero vale la pena investigar en este sentido. Una razón importante es que podría permitir evaluar la relación entre aspectos puramente consumistas y otros de naturaleza solidaria, en diarios de diversas orientaciones.

James Twitchell (1996), enumera seis características de la publicidad que ayudan a entenderla mejor. Twitchell dice que la publicidad es ubicua, anónima, simbiótica, sincrética, profana y mágica. Las dos primeras de estas características son fáciles de entender, pues, en efecto las imágenes publicitarias se encuentran en todas partes, casi literalmente dicho. Además, en efecto, no llevan firmas de autores. Las otras cuatro son sumamente interesantes, y dan lugar a otra línea de investigación. Que la publicidad sea simbiótica significa que ella, sostiene este autor, comparte "la energía de otros fenómenos sociales". La publicidad se mezcla con manifestaciones de todo tipo, desde la cultura popular a la cultura de las artes plásticas, la literatura, la música, las ciencias, la tecnología, etc. Una imagen publicitaria, por ejemplo, puede aparecer en relación simbiótica con canciones populares famosas o servir de base a una pintura destacada. También, ofrecerse como la solución a inveterados problemas de salud.

La publicidad conlleva también la característica de ser sincrética, esto es, ella se sitúa como una capa superior a aquellas manifestaciones con que se ha simbiotizado. Twitchell señala que es similar a lo que, por ejemplo, ha hecho el cristianisnmo con todo tipo de fenómenos tradicionales con los cuales ha logrado simbiotizarse, siempre situándose en la cúspide. Esto es conocido en sectores de pueblos primeras naciones que han mezclado sus tradiciones religiosas o folklóricas con los rituales de alguna iglesia cristiana.

La quinta característica es la de ser profana. Esto es, ella funciona primordialmente en esta tierra, en lo más mundanal, puesto que se trata de atraer la atención a la compra de productos o de servicios concretos. Aun en aquellos casos en que se hace mención de algo divino o metafísico, el punto no es ir hacia esas dimensiones, sino a las mundanales de la obtención de mercancías.

Sin embargo, la característica anterior, tiene relación con la sexta, la de ser mágica. Twitchell dice que es, tal vez, la más importante de las seis características. Los productos a que se refiere la publicidad, en general, no tienen otro valor más que su potencial utilidad, concreta, objetiva, pero, esto no es suficiente para querer adquirirlos. La publicidad los dota de un valor especial, que puede incluso transformar la vida. John Berger (1977) se refiere a este mismo fenómeno cuando dice que la publicidad "nos propone que nos transformemos, o que transformemos nuestras vidas, comprando algo más". Por lo tanto, la publicidad nos hace sentir que la compra de productos es más que simplemente la satisfacción de alguna necesidad específica. Consiste, además, en la sensación de haber alcanzado un estado más allá de la realidad concreta de la vida.

Finalmente, Twitchell (1996) agrega, a propósito de esta característica, que ella hace de la publicidad algo similar a la religión. Esta relación es sumamente sugerente, así dice este autor: 
En un sentido muy profundo, la publicidad y la religión son parte del mismo proceso de crear significado: ambas ocurren en los márgenes de la preocupación humana por el mundo que nos rodea, y cada cual intenta cerrar la brecha entre nosotros y los objetos proporcionando una manera de entender sistemática. Mientras que la Gran Cadena del Ser organizaba el mundo de nuestros antepasados, el mercado de objetos lo hace para nosotros. En ambos casos se promete redención: una a través de la fé, el otro a través de compras (p. 30).

Estas cuatro últimas características pueden servir de base a una creativa investigación de la publicidad en la prensa o, por cierto, en los medios de comunicación de masas en general. Asumiendo que Twitchell tiene razón, se podría llegar a tener un cuadro bastante sofisticado de la naturaleza de la publicidad.

John Berger (1977) sugiere un tipo de investigación que relaciona la publicidad con las artes plásticas, y en especial, con la pintura. No es inusual encontrar imágenes publicitarias que muestran directamente esa relación, como sería el caso de un aviso en que una pintura sirve de contexto a un producto o servicio. Berger se refiere también a imágenes de la publicidad que resultan ser pastiches de algunas pinturas famosas. "La Gioconda" de Leonardo da Vinci es usada frecuentemente en este sentido.

Sin embargo, John Berger va mucho más allá. Lo que propone es extraordinariamente sugerente, pues según su manera de entender la relación entre pintura y publicidad, esta última continuaría la tradición artística que se inicia en occidente con el Renacimiento. El argumento es profundo y vale la pena estudiarlo con cuidado, pero excede los límites y propósitos de este artículo. En resumen, el punto puede presentarse de la siguiente manera. Con el advenimiento del Impresionismo y las corrientes pictóricas que lo continúan, la tradición renacentista se ve cuestionada en varios aspectos esenciales, y uno de ellos es el tratamiento del espacio plástico: en un plano de dos dimensiones no es posible representar la tercera dimensión. Sin embargo, la publicidad continúa la tradición renacentista, y para ello hace uso de la fotografía, y más adelante, con el desarrollo tecnológico, de la fotografía a color. En este sentido, según Berger, hay una continuidad estilística entre la tradición renacentista referida y la publicidad. Pero este autor propone investigar mucho más todavía. En este sentido, dice que hay relaciones no solo de estilo, sino también de contenidos, lo que lo lleva a proponer investigar las similitudes entre la pintura de tradición renacentista y las imágenes publicitarias.

Temas que Berger propone para esta investigación son, entre otros, los siguientes: los gestos de las modelos en la publicidad, comparados con los gestos de las figuras mitológicas en las pinturas; el uso romántico de la naturaleza en orden a crear un lugar donde se pueda reencontrar la inocencia; la atracción exótica y nostálgica de varios lugares de la Tierra; el estereotipo de la mujer; el énfasis de carácter sexual con que se muestran las piernas de las mujeres; el mar, como ofreciendo una nueva vida; la apariencia física de los hombres para mostrar riqueza y virilidad; la ecuación entre beber bebidas alcohólicas y tener éxito. 
Finalmente, se presenta la última de estas seis líneas de investigación de la publicidad en la prensa. Se trata de una línea muy novedosa, que todavía está en sus comienzos, pero que dada su base teórica, podría resultar de mucho beneficio. Esta línea investiga la naturaleza de la argumentación en la publicidad, y tiene su origen en el desarrollo de la Teoría de Argumentación, y en particular, de la concepción de Michael Gilbert (1997) que se denomina Argumentación Multi-Modal.

Según esta teoría, todo estudio de la argumentación requiere distinguir al menos cuatro modos de argumentar. Ellos son el modo lógico tradicional que caracteriza a la sociedad occidental; el modo emocional; el modo físico-corporal, incluyendo en este a lo visual; y el modo intuitivo. De esta manera, al estudiar cualquier manifestación argumentativa, se debe proceder distinguiendo la aparición en ella de uno o más de esos modos. En rigor, algunos argumentos pueden ser primordialmente emocionales, intuitivos, visuales o lógicos; pero también pueden ser combinaciones de dos o más de esos modos.

Algunos teóricos de la argumentación, y son pocos por ahora, han comenzado a aplicar esta teoría a la investigación de la argumentación en la publicidad. La principal investigadora en esta línea es Louise Ripley $(2008,2010,2011)$, profesora de Marketing Social en York University. En lo que sigue, y para concluir este artículo, se presenta resumidamente su trabajo hasta ahora, el cual puede ser estudiado en detalle en los tres artículos acá referenciados.

Aplicando la teoría de Gilbert a las imágenes publicitarias, Ripley ha logrado mostrar la complejidad envuelta en las argumentaciones que ellas conllevan. Paso a paso, Ripley explora cada imagen tratando de mostrar los diversos aspectos envueltos en la argumentación. Así, es posible encontrar modos predominantes en la publicidad, es decir, imágenes de carácter principalmente lógico, emocional, visual o intuitivo.

Pero, también, una imagen publicitaria puede manifestar los modos en diversas proporciones. En un caso, por ejemplo, la imagen podría ser más emocional y visual que lógica o intuitiva. Por supuesto, un estudio de largo aliento podrá arrojar conclusiones sumamente interesantes para entender la naturaleza de la argumentación en la publicidad tal como aparece en la prensa. Cabe mencionar que la segunda línea de investigación discutida antes, tiene relación muy cercana con esta última, por cuanto un estudio de los aspectos racional y noracional o irracional de la prensa evidentemente puede beneficiarse de una investigación sobre los argumentos en la publicidad.

\section{Reflexiones finales}

En conclusión, en este trabajo se comenzó examinando la relación entre la publicidad y la sociedad capitalista, lo que llevó a concluir que la evaluación de la publicidad parece depender estrechamente de la evaluación que se haga del capitalismo.

Sobre esa base, sin embargo, se planteó la necesidad de investigar más a fondo la naturaleza 
de la publicidad. Existen numerosas líneas de investigación de la publicidad de las cuales hemos examinado seis que son menos frecuentes y que podrían ofrecer nuevas perspectivas, sobre todo si las aplicamos en países donde a la fecha no se han constatado estas propuestas. Tal puede ser el caso de países de economías emergentes como Chile.

Sin duda, cada una de estas líneas no excluye a las otras, aunque es difícil visualizar que una o pocas personas, puedan desarrollarlas todas a la vez. Obviamente, se requiere trabajo en equipo.

\section{Referencias bibliográficas}

Berger, J. (1977). Ways of Seeing. Harmonsworth: British Broadcasting, Corporation and Penguin Books.

Gilbert, M. (1997). Coalescent Argumentation. Mahwah, New Jersey: Lawrence Erlbaum Associates, Publishers.

Gloag, J. (1959). Advertising in Modern Life. London, Melbourne, Toronto: Heinemann.

Lindstrom, M. (2011). Brandwashed. New York: Random House.

Macpherson, C. B. (1962). The Political Theory of Possessive Individualism. London Oxford New York: Oxford University Press.

Macpherson, C. B. (1973). Democratic Theory: Essays in Retrieval. Oxford: Clarendon Press. Marx, K. (1954). CAPITAL. Moscow: Foreign Languages Publishing House.

Packard, V. (1957). The Hidden Persuaders. New York: D.K. McKay.

Ripley, M.L. (2008). Argumentation Theorists Argue That an Ad is Argument. Argumentation: An International Journal on Reasoning, 22, 507-519

Ripley, M. L. (2010). Gilbert's Multimodal Argumentation Model and the Psychology of Persuasion in Advertisements. En Csapo, J. y Andor, M. (Eds.), Psychology of Persuasion (pp. 149-169). New York: Nova Science Publishers, Inc.

Ripley, M.L. (2011). Argumentation and Emotional Cognition in Advertisements. En Zenker, F. (Ed.), Argument Cultures: Proceedings of the 9th International Conference of the Ontario Society for the Study of Argumentation (OSSA), May 18-21, 2011, University of Windsor, Windsor, Ontario: (CD ROM), pp. 1-11.)

Siebert, F.S., Peterson, Th., Schramm, W. (1984). Four Theories of the Press. Urbana and Chicago: University of Illinois Press.

Silva Vildósola, C. (1938). Medio Siglo de Periodismo. Santiago: Editorial Zig Zag.

Twitchell, J. (1996). ADCULT USA. New York: Columbia University Press. 